EESTI NSV TEADUSTE AKADEEMIA TOIMETISED. XVII KÖIDE KEEMIA * GEOLOOGIA. 1968, Nr. 3

ИЗВЕСТИЯ АКАДЕМИИ НАУК ЭСТОНСКОЙ ССР. ТОМ ХVII

ХимИЯ * ГЕОЛОГИЯ. 1968, №3 3

Т. ПЕХК, Э. ЛИППМАА

\title{
ХИМИЧЕСКИЕ СДВИГИ УГЛЕРОДА-13 АЛИЦИКЛИЧЕСКИХ СОЕДИНЕНИЙ
}

T. PEHK, E. LIPPMAA. SÚSINIK-13 KEEMILISED NIHKED ALITSOKLILISTES OHENDITES T. PEHK, E. LIPPMAA. CARBON-13 CHEMICAL SHIFTS OF ALICYCLIC COMPOUNDS

Бурке и Лаутербур $\left[{ }^{1}\right]$ измеряли химические сдвиги $\mathrm{C}^{13}$ во всех циклоалканах до циклогептадекана; в работах $\left[{ }^{3},{ }^{4}\right]$ изучены некоторые насыщенные гетероциклические соединения. Исследованию сложных спектров монорезонанса $\mathrm{C}^{13}$ замещенных и ненасыщенных сәединений, состоящих из многих перекрывающихся мультиплетов, посвящено сравнительно мало работ. Данные о химических сдвигах непредельных углеродных атомов в некоторых циклоалкенах приведены в $\left[{ }^{2,5-7}\right.$; сдвиги карбонильных групп моноциклических насыщенных кетонов изучались в работах $\left[{ }^{8}, 15\right]$. Насыщенные углеродные атомы в этих исследованиях не рассматривались.

Единственным методом получения от сложных соединений спектров $\mathrm{C}^{13}$, пригодных для интерпретации, является двойной резонанс. Регистрация спектров двойного резонанса на обычных спектрометрах, использующих развертку поля, - очень трудоемкий процесс $\left[{ }^{24}\right]$. Применение развертки измерительной частоты $\left[{ }^{2}\right]$ позволяет полностью развязать все протоны метиленовых групп лишь однократной (или максимально двукратной) перестройкой возмущающей частоты во время съемки спектра. Спектры $\mathrm{C}^{13}$ исследованных соединений были сняты на частоте 15,1 Мги с помощью ЯМДР-спектрометра, описанного ранее $\left[{ }^{2}\right]$. Почти исключительно применялись спектры абсорбции; разрешение и точность измерения химического сдвига от внешнего стандарта сероуглерода $\delta_{\mathrm{CS}_{2}}$ порядка 0,4 м. д. Результаты измерений приведены в таблице.

Нами было показано $\left[{ }^{16}\right]$, что химические сдвиги $\alpha$-углеродных атомов, соседних с двойной связью, сильно зависят от геометрической изомерии. В цис-изомерах $н$-алкенов наблюдаются диамагнитные и в трансизомерах -- парамагнитные сдвиги по сравнению с химическими сдвигами тех же атомов в соответствующем $н$-алкане. Химический сдвиг $\mathrm{C}^{13}$ $\alpha$-метиленовых групп составляет 167,3 м. д. в цис-циклооктене и 157 (точнее 158,6$)$ м. д. в транс-циклооктене $\left[{ }^{7}\right]$, что тоже соответствует диамагнитному (цис) и парамагнитному (транс) сдвигу относителььно циклооктана (165,6 м. д.; по данным [' $\left.{ }^{1}\right]$ 165,9 м. д.).

В то время как в $н$-алкенах влияние двойной связи не распространяется дальше $\alpha$-метиленовой группы, в циклоалкенах до $\mathrm{C}_{z}$ включительно такое влияние распространяется на весь цикл, и разница между химическими сдвигами $\beta$-и $\gamma$-углеродных атомов превышает 3 м. д. В циклогептене и цис-циклооктене сдвиг $\boldsymbol{\alpha}$-углеродного атома больше других химических сдвигов, а в циклогексене и особенно в циклопентене положение обратное. Очень большой парамагнитный сдвиг углеродных атомов $\alpha$-метиленовых групп ( 161,1 м. д.) по сравнению со сдвигом цик- 
Химические сдвиги $\delta$ cs, $_{\text {, }}$ герода-13 циклических соединений

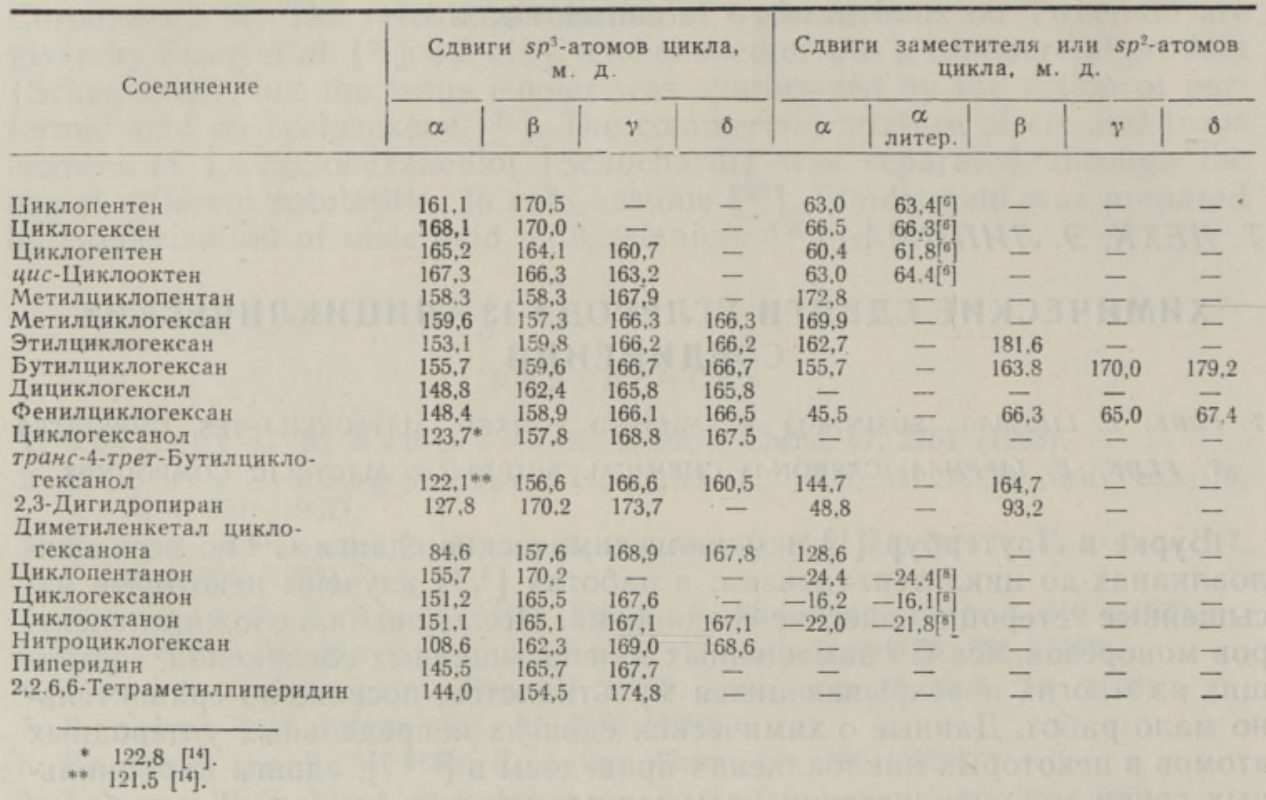

лопентана (167,2 м. д.) [ ${ }^{1}$ ], так же как и все другие необычные сдвиги, может быть обусловлен влиянием двойной связи на конформацию молекулы, хотя некоторая делокализация электронов в этих сравнительно малых циклах тоже не может быть исключена.

Обычно считают, что циклогексен имеет полукресловидную конформацию $\left[{ }^{9}\right]$ и угол у непредельных атомов составляет $124^{\circ}\left[{ }^{10}\right]$. Бартлет и Райс $\left.{ }^{11}\right]$ оценили величину этого угла в циклопентене в $112^{\circ}$, исходя из плоской конформации. Однако известно, что $\beta$-углеродный атом циклопентена не находится в плоскости остальных атомов цикла. В работе $\left[{ }^{12}\right]$ методами микроволновой спектроскопии найдено, что двугранный угол между плоскостями $s p^{2}, \alpha$ - и $\alpha, \beta$-атомов составляет 22 $16^{\prime}$; при использовании других данных этой работы угол у $s p^{2}$-гибридизованного атома составит $111^{\circ} 30^{\prime}$ - величину, очень близкую к полученной с плоской моделью. Последняя величина указывает на значительное напряжение в молекуле циклопентена. Между химическими сдвигами $\mathrm{H}^{1}$ и $\mathrm{C}^{13}$ в циклических соединениях нет заметной корреляции. В отличие от углеродных сдвигов, относительный химический сдвиг протонов $a$-метиленовой группы всегда парамагнитен $\left[{ }^{9}\right]$. Селективная развязка этих протонов позволила однозначно определить химические сдвиги $\alpha$-углеродных атомов. Сдвиги $\beta$ - и $\gamma$-углеродных атомов циклооктена отнесены по аналогии с соответствующими сдвигами циклогептена, в спектре которого интенсивности этих двух спектральных линий различны. В то время как химические сдвиги непредельных протонов циклопентена и циклогексена почти равны $\left[{ }^{9}\right]$, сдвиги $\alpha$-углеродного атома боковой цепи напряженных 1-алкилциклопентенов всегда диамагнитны $\left[{ }^{13}\right]$ по сравнению со сдвигами подобных атомов в 1-алкилциклогексенах.

Если считать, что химические сдвиги $\mathrm{C}^{13}$ метиленовых групп цикла определяются в основном конформацией молекул, и учитывать, что сдвиги $\mathrm{C}^{13}$ намного более чувствительны к конформации, чем сдвиги $\mathrm{H}^{1}$, то станет понятным влияние введения двойной связи на химические сдвиги удаленных углеродных атомов цикла. 
Исследование алкилпроизводных циклогексана и циклопентана показало, что влияние насыщенного заместителя не распространяется дальше замещенного атома и его непосредственных соседей.

В спектрах двойного резонанса $\mathrm{C}^{13}$ циклогексанола, его трет-бутилового производного и нитроциклогексана легко определяются все химические сдвиги. Сдвиги циклогексанола, приведенные в $\left[{ }^{17}\right]$, завышены на 1 м. д. в результате применения вторичного стандарта - бензола.

Сравнение спектров нитроциклогексана и циклогексанолов со спектром циклогексана показывает, что сдвиги $\mathrm{C}^{13}$ цикла определяются не только индуктивными, но и конформационными эффектами или даже сверхсопряжением. Для циклогексанола величина $-\Delta G^{\circ}$ оценена в $0,25 \div 1,25 \kappa \kappa a \Omega /$ моль [ $\left.{ }^{18}\right]$, что соответствует преимущественной экваториальной ориентации гидроксила при $25^{\circ} \mathrm{C}$ от 60 до $90 \%$; соответствующая цифра для нитроциклогексана от 85 до $100 \%\left[{ }^{19}, 20\right]$. Несмотря на отсутствие прямого 1,4-взаимодействия, в этих молекулах все же появляется чередование химических сдвигов.

В отличие от протонного спектра $\left[{ }^{21}\right]$, в спектре $\mathrm{C}^{13}$ 2,3-дигидропирана удается различать и относить все химические сдвиги, используя для этого аналогию со сдвигами тетрагидропирана $\left[{ }^{3}\right]$ и циклогексена.

Протонный спектр пиперидина был исследован в работе $\left[{ }^{22}\right]$, где не удалось установить разницы между сдвигами $\beta$ - и $\gamma$-протонов. Разница между химическими сдвигами соответствующих углеродных атомов 2 м. д. В спектре 2,2,6,6-тетраметилпиперидина неожиданным является очень слабое влияние двух метильных групп на химический сдвиг $\alpha$-углеродных атомов и их большое влияние на $\beta$-и $\gamma$-углеродные атомы.

Полученные нами сдвиги карбонильных углеродных атомов циклических кетонов прекрасно совпадают с данными работ $\left[{ }^{8},{ }^{15}\right]$. В отличие от замещенных полярными заместителями алифатических соединений и циклоалканов, химические сдвиги $\alpha-, \beta-, \gamma$ - и $\delta$-углеродных атомов увеличиваются монотонно с расстоянием от карбонильной группы. Это может быть вызвано нарушением 1,4-взаимодействия, но тогда остается непонятным, почему этот эффект сохранялся в циклогексаноле. В циклических кетонах, так же как и в циклоалкенах, нет параллелизма между химическими сдвигами $\mathrm{C}^{13}$ и $\mathrm{H}^{1}$. В протонном спектре циклопентанона сдвиги $\alpha$-и $\beta$-протонов практически равны $\left[{ }^{9}\right]$, но сдвиги углеродных атомов различаются на 15 м. д.

Интересно отметить, что химические сдвиги карбонильного углерода циклических кетонов коррелируются с объемами удерживания тех же кетонов на полярной жидкой фазе в газовой хроматографии $\left[{ }^{23}\right]$.

В диметиленкетале циклогексанона сдвиги углерода указывают на существование взаимодействий, свойственных циклогексанолу и нитроциклогексану.

\section{ЛИТЕРАТУ РА}

1. Burke J. J., La uterbur P. C., J. Am. Chem. Soc., 86, 1870 (1964).

2. Lippma a E., Pehk T., P a st J., Изв. АН ЭССР, Физ. Матем., 16, № 3, 345 (1967).

3. Maciel G. E., Savitsky G. N., J. Phvs. Chem., 69, 3925 (1965).

4. Nash C. P., Maciel G. E., J. Phys. Chem., 68, 832 (1964).

5. S piesecke H., Shneider W. G., Tetrahedron Lett., 468 (1961).

6. S a vitsky G. B., N a mikawa K., J. Phys. Chem., 68, 1956 (1964).

7. Липпмаа Э. Т., Соколов В.Й., ОливсонА. И., Паст И. О., Реутов О. А., Докл. АН ССР, 173, 358 (1967).

8. St others J. B., L a u t er bur P. C., Can. J. Chem., 42, 1563 (1964).

9. Wiberg K. B., Nist B. J., J. Am. Chem. Soc., 83, 1226 (1961).

10. Bucourt R., Ha in ant D., Bull. Soc. Chim. France, 1366 (1965).

11. B a rtlett P. D., Rice M. R., J. Org. Chem., 28, 3351 (1963). 
12. R a th jens G. W., J. Chem. Phys.. 36, 2401 (1962).

13. Пехк Т., Р анг С., Э йзен О., Ли пп м а Э., Изв. АН ЭССР, Хим. Геол., 17, № 3, 296 (1968).

14. Buchanan G. W., Ross D. A., Stothers J. B., J. Am. Chem. Soc., 88, 4301 (1966).

15. Marr D. H., St ot her s J. B., Can. J. Chem., 45, 225 (1967).

16. Р а нг С., Липпм а а Э., Пехк Т., Эйзен О., Изв. АН ЭССР, Хим. Геол., 17, № 3, 294 (1968).

17. Реутов О. А., Ша ткина Н. С., Липпма а Э. Т., Пехк. Т. И., Изв. АН CCCP, OXH (1968) (в печати).

18. Eliel E. L., Angew. Chem., 77, 784 (1965).

19. Hof man W., Stef a niak L., Urbanski T., Witanowski M., J. Am. Chem. Soc., 86, 554 (1964).

20. Felt k a m p H., Fra nkl in N. C., J. Am. Chem. Soc., 87, 1616 (1965).

21. B hacca N. S., Johns on L. F., Shoolery J. N., NMR Spectra Catalog, Varian Associates, 1962.

22. W e it k a m p H., Korte F., Chem. Ber., 95, 2896 (1962).

23. Le d a a 1 T., Tetrahedron Lett., 4397 (1967).

24. P a 1 E. G., Gr a n t D. M., J. Am. Chem. Soc., 86, 2977 (1964).

$\begin{array}{cc}\text { Ннститут кибернетики } & \text { Поступила в редакцию } \\ \text { Академии наук. Эстонской ССР } & 9 / \mathrm{IV} 1968\end{array}$

EESTI NSV TEADUSTE AKADEEMIA TOIMETISED. XVII KÖIDE KEEMIA * GEOLOOGIA. 1968, Nr. 3

ИЗВЕСТИЯ АКАДЕМИИ НАУК ЭСТОНСКОИ ССР. ТОМ ХVII

ХИМИЯ * ГЕОЛОГИЯ. 1968, № 3

С. РАНГ, Э. ЛИППМАА, Т. ПЕХК, О. ЭИЗЕН

\section{ХИМИЧЕСКИЕ СДВИГИ УГЛЕРОДА-13 Н-ДОДЕЦЕНОВ И н-ДОДЕЦИНОВ}

S. RANG, E. LIPPMAA, T. PEHK, O. EISEN. SUSINIK-13 KEEMILISED NIHKED $n$-DODETSEENIDES JA $n$-DODETSUUNIDES

S. RANG, E. LIPPMAA, T, PEHK, O. EISEN. CARBON-13 CHEMICAL SHIFTS OF $n$-DODECENES AND $n$-DODECYNES

При исследовании спектров ядерного магнитного резонанса $\mathrm{C}^{13}$ непредельных соединений $\left[{ }^{1,2}{ }^{2}\right]$ нами были замечены некоторые закономерности, общие для всех исследованных нормальных алкенов и алкинов. Выяснилось, что влияние тройной или двойной связи не распространяется дальше соседнего насыщенного углеродного атома. При этом магнитная анизотропия тройной связи приводит к диамагнитному сдвигу этих соседних атомов, а характер влияния двойной связи зависит от геометрической изомерии молекулы. Разница химических сдвигов обоих непредельных углеродных атомов кратной связи является весьма характерной и может быть использована для определения положения этсй связи в нормальной цепи. Однако изученные ранее соединения (октены и октины) не позволяли определять положение, при котором химические сдвиги соседних непредельных атомов еще различимы. Для дальнейшего изучения влияния двойной и тройной связи на длинную насыщенную цепь были исследованы химические сдвиги $\mathrm{C}^{! 3}$ н-додеценов и н-додецинов. 